Journal of Social Sciences 6 (3): 324-329, 2010

ISSN 1549-3652

(C) 2010 Science Publications

\title{
Public Perception and the Future of the Illinois Dairy Industry
}

\author{
C. Matthew Rendleman, Phillip R. Eberle, William C. Peterson, Livy Coe and Nathan Schotte \\ Department of Agribusiness Economics, College of Agricultural Sciences, \\ Mail Code 4410, Southern Illinois University Carbondale, Carbondale, Illinois 62901
}

\begin{abstract}
Problem statement: Illinois dairy production is shrinking both absolutely and relative to other states. If historic trends continue growth will come from larger, more technologically and economically efficient dairy operations. Several expansions that could have slowed the decline have been thwarted by community opposition. This paradox, the need for change versus resistance to growth in dairy farming, motivated the study upon which this article was based. This study explored the reasons for the conflict with rural residents. Approach: A mail survey was conducted to identify characteristics correlated with a tendency to accept dairy as a neighbor. Results: Community acceptance was associated with residence in a traditional "dairy county" and with having other dairy experience. New residents in growing urban areas are less tolerant of dairy. Conclusion: Illinois dairy developers may face less opposition by looking for demographic characteristics that correlate with a favorable view.
\end{abstract}

Key words: Dairy, survey, rural-urban conflict, public perception and the future of the Illinois dairy industry

\section{INTRODUCTION}

Recent conflicts between dairy interests and exurban or rural residents highlight the problems of farming at the rural-urban fringe. In the case of the Illinois dairy industry the issue has not been so much how to preserve agriculture in the face of urban encroachment, but how to find the room to expand in an already "urbanized" countryside. There have been several cases in Illinois in which dairy farmers seeking to build large, new dairies have met with substantial resistance and animosity from members of the communities where they wanted to locate. In one instance plans for a 2,500 cow dairy were withdrawn due to the opposition of residents and community leaders (Anderson, 2000). Another large dairy was successfully established in Illinois after incurring significant delays and cost escalations due to legal challenges from a number of parties opposed to its development (Fuhrig and Morris, 2000). In areas experiencing urban encroachment or growth in rural residences, smaller established dairies have also experienced conflict from their new neighbors complaining about odor, flies, or runoff into streams. A dairyman with a 180 cow dairy chose to leave Illinois because of complaints from new residents about odor and manure spills in streams (Williams, 2003).
The process of urbanization continues in Illinois as in much of the rest of the country. The extent of urbanized area as defined by census more than doubled in the 40 years up to 1990 (Heimlich and Anderson, 2001). And, especially important in Illinois, nearly $80 \%$ of land used for new housing is outside urban areas. While in the 1950s urban areas grew as people left farms, recently urban areas themselves have expanded while their population densities have fallen (8.4-4 people per acre in 2000). This development can disrupt social and environmental patterns in the countryside.

Most farming activities, including dairying, have the potential to affect their communities in both positive and negative ways. The farm may stimulate local economic activity or create an attractive vista for all to enjoy. Some point out potential positives for farmers as well, such as increased opportunity for part-time employment and a ready labor pool for seasonal farm work (Heimlich and Anderson, 2001). The negatives, however, attract more attention. Agriculture may impede traffic on roadways and otherwise put a strain on community infrastructure. There may be real or perceived chemical pollution, noise, odor, or flies. Usually these issues are successfully resolved, particularly where neighborhoods are stable and their members have coexisted for some time. However, this

Corresponding Author: C. Matthew Rendleman, Department Agribusiness Economics, College of Agricultural Sciences, Mail Code 4410, Southern Illinois University, Carbondale, Illinois 62901

Tel: (618) 453-2421, Fax: (618) 453-1708 
peaceful coexistence can be disrupted when a new livestock operation seeks to locate in a community or even when an existing one undertakes a major expansion.

Aside from neighbor problems it would appear that Illinois has attributes and a market to sustain or expand its dairy industry. The state produces an abundance of feed crops, has a milder winter climate than its northern neighbors, borders states to the south having deficit milk production, and has a strong farming culture, yet only produces about one-fifth of the dairy products consumed in the state. The state produced around 1,925 million pounds of milk in 2009, (NASS). And production is not expected to increase substantially by 2018 (FAPRI, 2009).

Illinois' dairy production has been declining in terms of number of dairy farms, number of dairy cows, milk production volume and value of production (NASS). Nearby states of Iowa, Indiana and Wisconsin have experienced similar trends, although to a lesser extent (NASS). These trends in Illinois and its neighboring states result from the regional shift in milk production to the West and Southwest U.S. From 1978-1997, milk cow numbers increased by $64 \%$ in California, $94 \%$ in Idaho and $461 \%$ in New Mexico (NASS, 2002; 2007). This follows the trend of the increasing percentage of production by larger farms. Larger dairy farms tend to be profitable while smaller ones, on average, do not recover their cost of production (MacDonald et al., 2007). The Illinois dairy industry must adopt a more competitive structure in order to sustain or increase milk production. Opposition to growth by residents may contribute to Illinois' small dairy size and lack of economies of scale.

Objective: The objective of this research is to explore the perceptions of residents from selected Illinois counties who may be affected by the development of a new or expanded dairy farm in their community. Through survey response analysis we distinguish between individuals who will support a new or expanded local dairy from those who will oppose such expansion. That analysis is extended to differentiate communities that will support or oppose dairy due to their demographic makeup. Finally, we explore characteristics of communities such as their historical and cultural traditions in dairy farming that may serve as predictors of community acceptance.

Our more specific research objectives are: (1) Determine Illinois residents' perceptions of dairy as a neighbor. (2) Determine relationship between perceptions of dairy as neighbor and opinions about economic and environmental issues regarding dairy. (3) Determine how these perceptions and opinions are related to an individual's previous experience with dairy and agriculture as well as certain demographic factors.

\section{MATERIALS AND METHODS}

A mail survey was developed to obtain the measurements of perceptions of Illinois residents regarding dairy as a neighbor and its economic and environmental impact. The questions in the survey were developed with input from agriculturists and community leaders. Focus group meetings with farmers and community leaders were held in Clinton and Christian counties. Applied Research Consultants (ARC), a survey consulting group, was employed to conduct the focus group and aid in the survey instrument development. An electronic version of the survey was administered to Illinois Extension personnel to test and validate the instrument. The survey included questions about the demographic characteristics of the respondents as well as their opinions about a number of issues related to the environment, economic growth, industry, regulation, community activism, agriculture and dairy farming. The survey was mailed with a cover letter then followed with a follow-up letter and survey.

Most of the subjects who were surveyed were selected from 14 Illinois counties including six traditional dairy producing counties and eight that did not have significant dairy output. In choosing these counties secondary considerations were given to diversifying geographic location and demographic characteristics including population density and growth, household income, unemployment and non-farm employment. Some counties were chosen from each of the crop reporting districts in the State.

In these fourteen counties all cities having populations exceeding 15,000 were excluded and 300 adult residents were randomly selected from each county. The sample list was selected by InfoUSA of Omaha, Nebraska. An equal number of residents was selected from each county regardless of its population. Responses were not weighted, the responses of this and all other groups sampled represent the respondent group and not its general population in the county or state.

The questions constructed to measure resident perceptions of dairy as a neighbor, the economic and environmental impact and opinions toward adequacy of current regulation are presented in Table 1 . Differences in perception were initially tested using a Chi square test for the following demographics: dairy and nondairy counties, rural and nonrural residents, farm background, lived near dairy, political affiliation, gender, education and annual income. 
Table 1: Questions to measure Illinois residents' perceptions and opinions about dairy

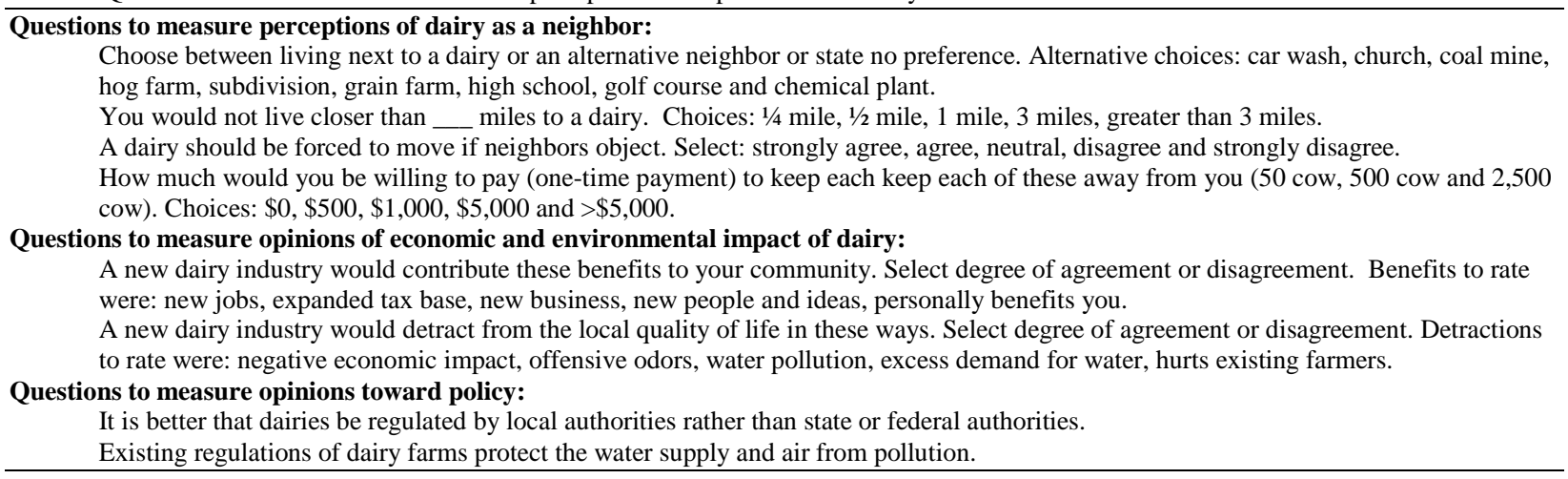

\section{RESULTS}

A summary of the respondent demographics, county and agricultural demographics of the study area are presented first. Of the 6,563 surveys mailed, 1,923 usable surveys were returned for a $29 \%$ response rate.

Respondent demographics: Sixty-nine percent of residents have lived in their community 18 years or longer. This suggests a very stable group of people whose long-term residence may be expected to influence their community attitudes and behavior.

Fifty-seven percent of residents commute more than one mile. Likely, many live in the country and commute to jobs in town.

Forty-one percent of the residents live in rural areas. This represents a large group of farmers' neighbors who are not themselves engaged in farming, a group that may have different attitudes and beliefs about living near a dairy than farmers.

Sixty-one percent of the residents have some education beyond high school and $24 \%$ have a bachelor's degree.

Almost $60 \%$ of residents were age 51 or older. To the extent that age influences attitudes and beliefs it is important to be aware that we are dealing with an older population in our study.

Seventy-five percent of respondents were male.

Sixty-six percent of respondents had dependents living at home. It is not known whether the dependents are minor children or elderly.

Eight percent had annual household income less than $\$ 15,000,31 \%$ reported between $\$ 15,001-\$ 39,999$, $28 \%$ were between $\$ 40,000-\$ 59,999,22 \%$ were between $\$ 60,000-\$ 90,000$ and $11 \%$ were greater than $\$ 90,000$.

For political affiliation, $45 \%$ of residents indicated Republican, 26\% indicated Democrat and 28\% indicated Independent or other.
Summary of county demographics: Although there were large differences between non-dairy and dairy counties in some of their demographics, there were even greater differences between counties within the two groups. The average population of dairy counties was somewhat higher. The range in population went from an urbanized 260,000 to a rural county with less than 9,000. Population density is considerably higher for dairy than non-dairy counties. Between all counties population ranged from 43-20 persons per square mile. Population growth during 1990-2000 was three times greater in dairy counties (USCB, 2000) perhaps because of the close-to-urban location formerly important in milkshed counties.

The poverty rate in 2000 in non-dairy counties was nearly double the rate for dairy counties. The unemployment rate was higher too: 6.4 versus $4.1 \%$ (USCB, 2000).

Educational achievement in non-dairy counties (that includes Champaign county, the home of University of Illinois) was somewhat higher than for dairy counties. The rate of growth in non-farm employment during 1990-1999 was 36.2\% in dairy counties versus $14.1 \%$ in non-dairy counties (USCB, 2000).

Summary of agricultural statistics: These agricultural statistics demonstrated significant differences between non-dairy and dairy counties for some measures and even greater differences within the groups for most measures. Some of the most noteworthy were: The average percentage of workforce employed in agriculture and forestry was similar for non-dairy and dairy counties at just below 5\%. However, the variation within both groups ranged from agrarian counties having more than $8 \%$ to those having about one percent of their workforce employed in agriculture.

Farm consolidation was more rapid in the dairy than non-dairy counties during the period 1992-1997 
(NASS, 2002). However, the number of acres in farmland remained fairly constant for both groups. Thus, both experienced growth in farm size, with more rapid consolidation in dairy counties.

The non-dairy counties were somewhat larger than the dairy counties based upon the market value of agricultural products sold, but there were substantial differences between individual counties. The range for all counties was from \$238-\$21 million (NASS).

The average size of farms in non-dairy counties was larger than the dairy counties in terms of both acreage and market value of products sold.

For non-dairy counties only $13 \%$ of the value of products sold was from livestock products. Livestock products represented $49 \%$ of agricultural products sold for dairy counties (NASS).

\section{Survey results:}

Benefits of a new dairy: Survey participants were asked to evaluate potential benefits a new dairy industry would contribute to their community and how it might detract from the local quality of life. The "new jobs" benefit was considered the most likely benefit of a new dairy industry with $64 \%$ of residents agreeing or strongly agreeing. "Expanded tax base" was perceived as a benefit by $58 \%$ of the residents. Relating these to living close to a dairy we found, not surprisingly, that residents who believe a new dairy industry results in new jobs are willing to live closer to a dairy and residents who believe a new dairy industry results in an expanded tax base are also willing to live closer (Table 2).

Detractions of a new dairy: Measuring perceived detractions from the local quality of life were the questions: "hurts existing farmers", "excess demand for water", "water pollution", "offensive odor" and "negative economic impact". Of these detractions, offensive odors was the item most agreed upon with $51 \%$ and only $17 \%$ in disagreement. Water pollution and excess demand were the second and third leading detractions with 37 and 33\%, respectively, in agreement. Relating these two problems to living close to a dairy, we found: Residents who believe a new dairy industry results in offensive odors, residents who believe a new dairy industry results in water pollution and residents who believe a new dairy industry results in excess demand for water want to live farther from a dairy (Table 2).

Preference for dairy as a neighbor: The residents were asked to state their preference given the choice of living next to a dairy or an alternative neighbor. A majority of Illinois residents preferred dairy as a neighbor over a chemical plant, hog farm, coal mine or car wash. They were split in their preference of living next to a dairy or a high school. And a majority preferred a subdivision, golf course, church or grain farm as a neighbor over dairy.

Demographic differences in perceptions towards dairy: Tests for significant differences in perceptions toward dairy were performed using Chi-Square tests. The results are summarized in Table 3. Significant differences at a level of $5 \%$ or less are reported.

Differences in perceptions between dairy and nondairy counties occurred for "distance from dairy", "offensive odors", "water pollution", "excess demand for water", "new jobs", "increase in tax base", "dairy forced to move" and "local regulations". Residents for all those questions were significantly more in favor of dairy than residents of non-dairy counties.

Table 2: Relationship between distance willing to live close to a dairy and other opinions

Residents who believe a new dairy industry results in new jobs are more willing to live close to a dairy.

Residents who believe a new dairy industry results in expanded tax base are more willing to live close to a dairy.

Residents who believe a new dairy industry results in offensive odors are less willing to live close to a dairy.

Residents who believe a new dairy industry results in water pollution are less willing to live close to a dairy.

Residents who believe a new dairy industry results in excess demand for water are less willing to live close to a dairy.

Residents who believe a new dairy should be forced to move are less willing to live close to a dairy.

Residents willing to pay to keep a dairy away prefer to live farther from a dairy.

Residents who believe existing regulations of dairy protect from pollution are willing to live closer to a dairy.

Residents who prefer local regulation have no particular preference towards how close to live to a dairy.

Table 3: Tests for differences in perceptions about dairy by demographic groups using chi-square for Illinois residents

\begin{tabular}{|c|c|c|c|c|c|c|c|c|c|c|c|c|}
\hline $\begin{array}{l}\text { Demographic } \\
\text { factor } \\
\text { favoring dairy }\end{array}$ & $\begin{array}{l}\text { Would } \\
\text { not live } \\
\text { closer than }\end{array}$ & $\begin{array}{l}\text { Offensive } \\
\text { odors }\end{array}$ & $\begin{array}{l}\text { Water } \\
\text { pollution }\end{array}$ & $\begin{array}{l}\text { Excess } \\
\text { demand } \\
\text { for water }\end{array}$ & $\begin{array}{l}\text { New } \\
\text { jobs }\end{array}$ & $\begin{array}{l}\text { Taxes } \\
\text { increase }\end{array}$ & $\begin{array}{l}\text { Dairy } \\
\text { forced } \\
\text { to move }\end{array}$ & $\begin{array}{l}\text { Pay } 50 \\
\text { cows }\end{array}$ & $\begin{array}{l}\text { Pay } 500 \\
\text { cows }\end{array}$ & $\begin{array}{l}\text { Pay } \\
2,500 \\
\text { cows }\end{array}$ & $\begin{array}{l}\text { Regulations } \\
\text { adequate }\end{array}$ & $\begin{array}{l}\text { Local } \\
\text { regulations }\end{array}$ \\
\hline Dairy (non-dairy) & $<0.01$ & $<0.01$ & $<0.05$ & $<0.01$ & $<0.01$ & $<0.01$ & $<0.01$ & NS & NS & NS & NS & $<0.01$ \\
\hline Rural (non-rural') & $<0.01$ & NS & $<0.05$ & NS & NS & $<0.01$ & $<0.01$ & NS & NS & NS & NS & NS \\
\hline Farm background & NS & NS & $<0.01$ & $<0.05$ & $<0.05$ & $<0.05$ & $<0.01$ & NS & NS & NS & $<0.01$ & $<0.01$ \\
\hline Lived near dairy & $<0.01$ & $<0.01$ & $<0.01$ & $<0.05$ & $<0.01$ & NS & $<0.01$ & NS & NS & NS & $<0.01$ & NS \\
\hline Male & $<0.01$ & NS & NS & NS & NS & $<0.05$ & NS & NS & NS & NS & NS & $<0.01$ \\
\hline Low to moderate income & NS & NS & NS & NS & NS & NS & NS & NS & $<0.01$ & $<0.01$ & NS & NS \\
\hline
\end{tabular}

Note: $<0.01$. This means the factor is significant at 1\%; NS: Not Significant difference of opinion 
Distance between dairy and residence: Survey participants were asked to complete the sentence, "You would not live closer than_miles to a dairy". The choices were $1 / 4,1 / 2,1$ and 3 miles and greater than 3 miles. The responses for those choices were $24,14,24$, 16 and $22 \%$ respectively. We chose this question to be our proxy to rate residents' perception of dairy because of uniform response over the range of choices of distance. Those willing to live closer to a dairy were found to be more favorably predisposed towards dairy than those wanting to live greater than 3 miles from a dairy. The "willingness to live nearby" was found to be the variable most reflecting the perceptions and attributes thought important in evaluating a respondent's favorability to dairy.

Factors found significant in cross tabs between distance from a dairy and other opinions about dairy support our assumption that the distance preference from a dairy provides a proxy for measuring favorable perceptions of dairy.

Forcing a dairy to move and willingness to pay to keep dairy away: Only $11 \%$ of the residents agreed that a dairy should be forced to move if neighbors object while $70 \%$ disagreed. Willingness to pay a onetime payment to keep a dairy away from a residence depended on the size of the dairy. Only 4\% Illinois residents were willing to pay to keep a 50 cow dairy from locating near their residence as compared to $18 \%$ willing to pay to keep a 500 cow dairy away and $24 \%$ were willing to pay to keep a 2500 cow dairy away. For the 2500 cow dairy, $6 \%$ were willing to pay $\$ 5,000$ or more compared to $3 \%$ for a 500 cow dairy and $0 \%$ for a 50 cow dairy. Residents who believe a new dairy should be forced to move want to live farther from a dairy and residents willing to pay to keep dairy away prefer to live farther from a dairy.

Opinions toward dairy regulation: Respondents were asked to state their agreement or disagreement to two policy statements concerning dairy regulation. (1) It is better that dairies be regulated by local authorities rather than state or federal authorities. (2) Existing regulations of dairy farms protect the water supply and air from pollution. In response to the first statement opinions were mixed but favoring local authority with $41 \%$ of the residents in agreement, $36 \%$ neutral and $22 \%$ in disagreement. In response to statement 2 , residents were unsure with $45 \%$ neutral and $37 \%$ in agreement. Residents who prefer local regulation have no particular preference towards how close to live to a dairy, but residents who believe existing regulations of dairy protect from pollution are willing to live closer to a dairy.

\section{DISCUSSION}

The results suggest that residents from dairy counties or individuals with agricultural backgrounds, or individuals with experience living near a dairy are more supportive of dairy. Those who were more knowledgeable of dairy and agriculture had a more favorable view. Sharp and Smith (2003) suggest that farmers at the urban-rural interface may benefit from developing social capital in the form of good relations with non-farm neighbors.

Air and water quality are the major concerns associated with a new dairy among residents. Any education or public relations program would have to address the odor and water quality issues and what dairymen are doing to safeguard air and water. Regarding the adequacy of regulations: Residents without farm backgrounds or experience living near a dairy are less sure that they are adequate.

Although most residents are against forcing a dairy to move, residents from non-dairy counties or without agricultural experience are more willing to force a dairy to move. Although most residents are unwilling to pay to keep a dairy away, residents are more willing to pay to keep a large dairy away than a small dairy especially if they have higher incomes. This has implications for the county or region chosen for expansion.

Producers wishing to expand their operations will find these results useful in considering dairy location. For those in Illinois desiring to sustain or expand milk production, the results suggest that an education or public relations program for residents may be important. New dairy farms are frequently large, turnkey operations that are highly visible and may be perceived to have widespread community impact. Residents may need to have regulations explained and be assured that they are adequate. Insights into this matter will be useful because of their potential to lessen conflict and related costs, both financial and nonfinancial, to the dairyman and the community.

\section{CONCLUSION}

Illinois dairy developers may face less opposition by looking for demographic characteristics that correlate with a favorable view.

\section{REFERENCES}

Anderson, C., 2000. Bellflower vote opposes megadairy. The Pantagraph. 
FAPRI, 2009. Agricultural Outlook. US Livestock and Dairy.

http://www.fapri.iastate.edu/outlook/2009/text/6US LivestockDairy.pdf

Fuhrig, F. and N. Morris, 2000. Californian rules out Christian County site. The State-Journal Register.

Heimlich, R.E. and W.D. Anderson, 2001. Development at the urban fringe and beyond: impacts on the agricultural and rural land. Economic Research Service, US Department of Agriculture, AER \#803, Washington DC. http://ideas.repec.org/p/ags/uerser/33943.html

MacDonald, J.M., W.D. McBride and E.J. O'Donoghue, 2007. Low costs drive production to large dairy farms. Economic Research Service, US Department of Agriculture, Amber Waves, Washington DC.

http://www.highbeam.com/doc/1P3-1350729301.html
NASS, 2002. USDA published estimate data base-U.S. and state level data: For dairy. http://www.nass.usda.gov:81/ipedb

NASS, 2007. Census of Agriculture. National Agricultural Statistics Service, U.S. Department of Agriculture (USDA).

http://www.agcensus.usda.gov/Publications/2007/F ull_Report/usv1.pdf

Sharp, J.S. and M.B. Smith, 2003. Social capital and farming at the rural-urban interface: The importance of nonfarmer and farmer relations. Agric. Syst., 76: 913-927. DOI: 10.1016/S08832927(02)00083-5

USCB, 2000. United States Census U.S. Census Bureau. United States Department of Commerce. http://quickfacts.census.gov/qfd/

Williams, N., 2003. Fourth-generation farm moving down the road. Illinois Agric. News, 27: C1. 